\title{
A Comparison of Postural Responses in a Virtual and a Real Environment, a Randomised Controlled Study.
}

Patrice Piette ( $\sim$ patrice.piette@pole-sthelier.com )

Pole Saint Helier, rehabilitation center, Rennes, Britanny

Emilie Le Blong

Pole Saint Helier, rehabilitation center, Rennes, Britanny

Maxime Gilliaux

Hospital La Musse, Saint Sébastien de Morsent

Mathilde Collet

Hospital La Musse, Saint Sébastien de Morsent

Romain Cavagna

Artefacto, Betton, Brittany

Bastien Fraudet

Pole Saint Helier, rehabilitation center, Rennes, Britanny

Philippe Gallien

Pole Saint Helier, rehabilitation center, Rennes, Britanny

\section{Research Article}

Keywords: virtual reality, balance, center of pressure, security, tele-rehabilitation

Posted Date: September 16th, 2021

DOI: https://doi.org/10.21203/rs.3.rs-872864/v1

License: (1) (1) This work is licensed under a Creative Commons Attribution 4.0 International License. Read Full License 


\section{Abstract}

\section{Background}

Immersive virtual reality solutions are seeing increasing usage in functional rehabilitation programmes. However, there is no reference that allows us to confirm that these environments present the same characteristics and therefore the same degree of safety and training in postural responses for balance.

\section{Question}

The aim of the study was to compare displacements from centre of gravity (distance covered and surface used) in balance tests, comparing the real situation to an identical virtual situation.

\section{Participants}

70 healthy subjects aged between 18 and 65 were recruited in two centres.

\section{Design}

The study used a one-way repeated-measures design with randomisation of the order in which the two test conditions were performed.

\section{Intervention: .}

The first test condition was "real", taking place in a bedroom of a treatment centre apartment, and the second was virtual, with the room reproduced and seen through a HMD. For each condition, two static tests (left leg, right leg) and two dynamic tests (left and right) were performed. Each test included three attempts.

\section{Outcome measures}

The displacement from the centre of gravity was recorded on a force plate.

\section{Result}

69 participants completed all of the tests and were analysed. None of the tests resulted in confirmation that the virtual was equivalent to the real (Two One-Sided Tests for left static, right static, left dynamic, right dynamic; surface respectively $p=0.592, p=0.151, p=0.238, p=0.503$; distance respectively $p=$ $1.00, p=0.91, p=0.0742, p=1.00$ ). Furthermore 6 tests of out 8 showed a significant and considerable difference (surface respectively $p=0.00249, p=0.0664, p=0.0318, p=0.00483$; distance respectively $p=$ $1.12 \times 10-8, p=5.27 \times 10-5, p=0.153, p=2.55 \times 10-9$ ).

\section{Conclusion}


Postural responses were poorer in the immersive virtual environment, both on the static and dynamic balance tests. The offer of balance rehabilitation in immersive VR raises safety issues and consequently ethical issues that are as yet unresolved. Researchers must test solutions to correct this serious problem.

Trial registration: The study is registered at the US National Institutes of Health (ClinicalTrials.gov) NCT04574726

\section{Introduction}

Virtual Reality (VR) has been used to improve balance in patients who have had a CVA, patients with neuro-degenerative conditions and elderly people ${ }^{123}$. However, usability and efficacy have in the main been studied on the basis of systems that offer low or moderate immersion, such as the Wii or Kinect. The use of an immersive system (VR, high immersion) tends to demonstrate additional benefits 45678 such as treating pain in phantom limbs or improving walking by introducing visual landmarks.

We wanted to identify the procedures for validating an immersive virtual environment (with Head Mounted Display, HMD) in balance training.

Balance is a complex skill made up of three sub-systems that work together to keep us in contact with our environment and to give us the ability to react to current conditions and prepare for future changes. These sub-systems are the proprioceptive system, vestibular system and vision. Immersive VR completely modifies our visual perception of the surrounding environment and this can lead to information that contradicts that which we are perceiving through the other sub-systems involved in balance, proprioception and the vestibular system, which produces discomfort, motion sickness and loss of balance ${ }^{9}$. The properties of the pressure centres on force plates (area, trajectory, distance covered) have been analysed to evaluate balance performances in patients post-CVA ${ }^{10}$, people with $\mathrm{MS}^{11}$, people with Parkinson's disease ${ }^{12}$ and elderly people ${ }^{13}$. A virtual environment can therefore be validated by comparing the characteristics of COP (centre of pressure) through static and dynamic balance exercises in a real environment and the same environment translated into immersive virtual reality.

Few studies have put forward a full validation procedure. Using a HMD with a smartphone, Woo et al. showed that the COP area and oscillations increase in single-leg balance ${ }^{14}$. The device did not assess balance in displacements of the head or upper limbs. Morel et al compared COP in real and virtual situations using a ball-avoidance game ${ }^{15}$. They found an increase in response times and oscillation ranges in VR. No assessment of single-leg stance was made and the sample was small (18 participants).

Luo et al. compared COP through three types of visual stimulation, using vertical, horizontal and concentric lines in real and VR environments, without finding any significant difference between the two, but the device did not test balance with mobility of the head or upper limbs ${ }^{16}$. In the Kim study looking at walking in a virtual environment, the data showed that postural control measured by oscillation of COP was not affected by VR, with patients free to look around in an urban landscape ${ }^{17}$. This study did not 
assess the patient in a precarious balance (single-leg stance). Horlings et al studied the influence of virtual reality on postural stability during gentle posture movements with feet together and feet in tandem 18. It found that VR led to an identical deterioration in balance as seen in the same situation with eyes closed. However, this study used older generation HMD which is less effective.

Robert et al. validated a virtual environment using the functional reach test for patients with cerebral palsy and showed that movement was slower with a slightly reduced range compared to the test in a real environment ${ }^{19}$. COP was not measured with head displacement or in single-leg stance. The same author carried out a study in 14 adults in good health and examined the effects of using a HMD for 3 minutes on static and dynamic balance ${ }^{20}$. The study found that, even though there was no significant difference in static balance when using a HMD, there was a significant difference in dynamic balance; however, the sample was small.

It is also thought that a difference in postural responses could affect the transfer of learning. This is the process by which a person's participation in an activity influences, either positively or negatively, how this same person carries out the activity at a later time ${ }^{21}$. The acquisition of movement results in the construction of a new motor programme and these programmes appear to be relatively fixed and not especially transferable. Motor learning is very specific and a transfer is only seen in cases when there is a very strong similarity between the situation in which the skill was learned and the transfer situation ${ }^{22}$. The conditions for similarity are: the general shape of the gesture; the rhythmic structure; the perceived relationship between body and environment; the type of motor facilitation; tactical principles; biomechanical principles; and finally psychological attitudes (role played by success and failure).

As a result, sensory impulses involving different postural responses from one context to the other (VR and R) will introduce motor acquisitions that are partly non-transferable to reality ${ }^{23}$.

The studies very often also report assessments of a sensation of motion sickness, sometimes observed in immersive virtual reality environments. The SSQ (Simulator Sickness Questionnaire) was updated in 1993 and is used a reference for the vast majority of studies ${ }^{24}$ although its validity for use in virtual reality is open to question. A variant adapted for virtual reality, the VSSQ, was studied by Kim et al. ${ }^{25}$, however the psychometrics of this version perform less well than the SSQ. Motion sickness appears to be more common in women ${ }^{26}$, and this is also found with immersive VR ${ }^{27}$.

The two elements that were therefore chosen to study postural responses in a virtual environment were COP and motion sickness.

Immersive VR may offer greater efficiency in rehabilitation of balance and motor skills for complex patients. The technical features of the environments, scrolling speed in three dimensions and angulation mean that equivalent postural reactions in VR and reality can be ensured. This validation is a crucial element in the development of VR and in remote rehabilitation. It is essential for patient safeguarding as patients must not be exposed to danger during VR sessions. 
Furthermore, there is no clear proof in the literature of the equivalence of postural responses between comparable real world conditions and virtual reality in a static and dynamic balance exercise.

\section{Specific Objectives}

The main objective of this study is to check the equivalence of postural responses in both situations, real and virtual, in similar environments, measured by the displacement of the centre of pressure, distance covered and surface used. The secondary objective is to ensure there are no side effects of motion sickness.

\section{Method \\ a. Design}

This study uses a one way repeated measures design ${ }^{28}$ with randomisation of the order in which the two test conditions were performed. The study follows the recommendations of CONSORT $2010^{29}$. It has been registered with clinical trials.gov prior id $^{\circ}$. NCT04574726

The experiment was performed with national ethical committee approval on 17/09/2020 and in accordance with the ethical standards laid down in the 1964 Declaration of Helsinki.

\section{b. Sample size}

Cohen's $d$ for calculating the detectable internal equivalence was performed using the TOSTER package version 0.3.4 under r statistic, "powerTOSTpaired" function.

The equivalence bounds to achieve $80 \%$ power for a small effect: -0.35 and 0.35 correspond to a sample of 70 matched participants.

\section{c. Participants}

Two recruitment centres were used, Pôle St Hélier, a continued care and rehabilitation centre in Rennes, and La Musse Hospital in Evreux.

The inclusion criteria were:

healthy individuals aged between 18 and 65 . We excluded people with severe vision disorders, vestibular disorders, orthopaedic disorders of the lower limbs, orthopaedic disorders requiring an upper limb brace, pregnant women and people with a score of over 25 on the MSSQ ${ }^{30}$. The participants signed two copies of a Free and Informed Consent Form. 


\section{d. Randomisation}

Each participant performed the balance tests under both conditions: in a real environment and a virtual environment. A list with the randomisation of the order in which the real/virtual tests were performed was prepared in advance by a blinded operative (random function in excel).

\section{e. Intervention}

A real space was scanned so it could be translated into virtual reality (Figure 1). The subject was positioned in a hospital room opposite the bed. The volume of the room and its furniture, wall displays, window and shadows was reproduced. A red chair was placed to the left of the bed to provide a contrasting visual landmark. The virtual environment was loaded on to an Oculus Quest 1 (Consumer Edition, Facebook, United States). Once in position opposite the bed, each subject could follow the instructions whether in the real environment or the virtual one.

A force plate (Tyromotion Tymo plate) was positioned on the floor in front of the bed. The virtual environment was configured to be consistent with the real environment in terms of the position and distances to furnishings. The Tymo plate recorded displacements from the Centre of Pressure (COP).

Each participant went through a cycle of four successive assessments:

1. static single-leg, left foot $30 \mathrm{sec}$.

2. static single-leg, right foot $30 \mathrm{sec}$.

3. dynamic single-leg, left foot $30 \mathrm{sec}$.

4. dynamic single-leg, right foot $30 \mathrm{sec}$.

The dynamic test involved linking a series of movements. Displacement of the upper limbs and head in three dimensions were configured as follows (Figure 2):

Starting position: single-leg balance, upper limbs (UL) by the sides

- Movement 1: elevation of UL in maximum flexion for 6 seconds

- Movement 2: UL lowered towards the opposite side from the standing leg until horizontal in 3 seconds

- Movement 3: horizontal displacement from one side to the other in 6 seconds

- Movement 4: UL lowered towards the starting position in 3 seconds.

Each participant had 3 attempts for both the virtual and real environment in the randomised order.

\section{f. Outcomes}




\section{primary outcome}

The primary outcome measure is displacement of COP recorded during the balance tests:

- Surface of COP in $\mathrm{cm}^{2}$ measured during the tests.

- Distance covered by COP in $\mathrm{mm}$

\section{secondary outcome}

The potential side effects of immersive virtual reality were measured afterwards on the SSQ ${ }^{31}$. "Cyber sickness" occurs where there is a conflict between vestibular and visual input demonstrating latency of the virtual environment relative to head displacement. If the SSQ scores are high, the loss of balance could be attributable to the configuration of the virtual environment.

\section{g. blinding}

Each participant performed the tests according to the randomisation arm they were allocated to using a previously drawn-up list. The assessors created a patient identity in the software using the enrolment number followed by the experimental arm. The assessor monitored the tests being performed and the recordings of the pilot software of the plate for capturing the centre of gravity; no data on test performance could be modified by the assessor.

\section{h. statistical methods}

The data were processed using the equivalence test: Two One-Sided Tests Procedure (TOST) ${ }^{32}$ on paired data ${ }^{33}$.

The statistical tests were carried out using the TOST package and the function "TOSTpaired". To exclude confounding bias, we sought to find out whether the order of test environments had any influence on performance ( $\mathrm{t}$ test between the two arms), and whether there was any learning over the 3 series of tests requested (Kruskall-Wallis on each series of 3 tests for 4 tests in the real environment and 4 tests in the virtual environment).

\section{Results}

\section{a. Recruitment}

Between 15 October 2020 and 21 January 2021, 70 subjects were recruited at Pôle St Helier and at La Musse Hospital; 40 and 30 respectively. One person chose to withdraw from the tests due to the onset of 
knee pain during the single-leg stance. All the other participants performed all 6 attempts: 3 real, 3 virtual, making a total of 24 balance tests. For each test, the distance and surface of the COP were recorded. 48 variables were collected for each participant. The data of 69 participants were analysed (Fig. 3).

\section{b. Baseline data}

The mean age was 33 years (SD 11.38). There was an even male/female split (35/34).

The majority of the population were right-handed (60), with eight who were left-handed and one person who proved to be ambidextrous. 36 participants were in arm 1: real environment then virtual, 33 were in arm 2, virtual then real. No incidents requiring reporting occurred during the participants' tests. The mean of the score for sensitivity to motion sickness was low (mean 5.20 SD 4.98) compared to mean normal values (mean 12.9 SD 9.9) ${ }^{30}$. There was no difference between men and women in this respect ( $p$-value $=0.1334)($ Table 1$)$

Table 1

Demographic and clinical characteristics of participants ; center $1=$ Pôle St Helier, center 2 = La Musse Hospital ; random order: Harm 1 = reel virtual, Harm 2 = order Virtual Reel ; MSSQTot = Motion sickness susceptibility questionnaire.

\begin{tabular}{|llll|}
\hline Rehabilitation center & & & \\
\hline & Center 1 & Center 2 & Pool \\
\hline Arm & 39 & 30 & 69 \\
\hline Sex & $1: \mathrm{n}=36$ & $2: \mathrm{n}=33$ & \\
\hline Age $($ mean, sd) & $\mathrm{M}=20, \mathrm{~F}=19$ & $\mathrm{M}=15, \mathrm{~F}=15$ & $\mathrm{M}=35, \mathrm{~F}=34$ \\
\hline Weight $(\mathrm{kg})($ mean, sd) & $65.99(9.87)$ & $72.58(15.58)$ & $68.86(12.99)$ \\
\hline Size $(\mathrm{cm})($ mean, sd) & $171.41(7.73)$ & $169.7(8.61)$ & $170.67(8.11)$ \\
\hline MSSQTo (mean, sd) & $7.02(5.49)$ & $2.83(2.90)$ & $5.20(4.99)$ \\
\hline & Other data & & \\
\hline Laterality & Right handed $\mathrm{n}=60$ Left handed $\mathrm{n}=8$ Ambidextrous $\mathrm{n}=1$ \\
\hline Harm & $1: \mathrm{n}=36$ & $2: \mathrm{n}=33$ & \\
\hline
\end{tabular}

\section{c. Outcomes and estimation}

Analyses were made of displacement of Centre of Gravity: surface used and distance covered 


\section{Testing the equivalence of the real and virtual reality environments}

Based on the equivalence test and the null-hypothesis test combined, the observed effect (COP area and distance) is statistically not equivalent to zero for all performed tests. Thus, most of them (6/8) are statistically different from zero (Table 2) (Figs. 4 and 5). 
Table 2

$\mathrm{R}=$ real, $\mathrm{V}=$ virtual; null hypothesis test $=$ dependent $\mathrm{t}$-test; Equivalence Test $=$ two one-sided tests procedure; ${ }^{*} p<0.05 ; * \star p<0.005, * \star \star p<0.0005$

\section{Surface}

\begin{tabular}{|c|c|c|c|c|}
\hline & Mean (sd) & $\begin{array}{l}\text { Equivalence } \\
\text { Test }\end{array}$ & $\begin{array}{l}\text { Nul hyothesis } \\
\text { Test }\end{array}$ & $\begin{array}{l}\text { difference mean } \\
\text { [Cl] }\end{array}$ \\
\hline Left Static R & $1.34(0.98)$ & \multirow[t]{2}{*}{$p=0.592$} & \multirow[t]{2}{*}{$p=0.00249 * \star$} & -0.44 \\
\hline Left Static V & $1.78(1.85)$ & & & {$[-0.72-0.16]$} \\
\hline Right Static R & $1.47(1.04)$ & \multirow[t]{2}{*}{$p=0.151$} & \multirow[t]{2}{*}{$p=0.0664$} & -0.25 \\
\hline Right Static V & $1.73(1.12)$ & & & {$\left[\begin{array}{lll}-0.52 & 0.01\end{array}\right]$} \\
\hline Left DynamicR & $2.71(3.65)$ & \multirow[t]{2}{*}{$p=0.238$} & \multirow[t]{2}{*}{$p=0.0318^{*}$} & -0.7 \\
\hline Left DynamicV & 3.47 (2.12) & & & {$[-1.45-0.06]$} \\
\hline Right Dynamic & $2.422(2.50)$ & \multirow[t]{3}{*}{$p=0.503$} & \multirow[t]{3}{*}{$p=0.00483^{\star \star}$} & -1.27 \\
\hline & & & & {$[-2.15-0.40]$} \\
\hline $\begin{array}{l}\text { Right Dynamic } \\
\text { V }\end{array}$ & 3.70 (3.70) & & & \\
\hline \multicolumn{5}{|l|}{ Distance } \\
\hline & Mean (sd) & $\begin{array}{l}\text { Equivalence } \\
\text { Test }\end{array}$ & $\begin{array}{l}\text { Nul hyothesis } \\
\text { Test }\end{array}$ & $\begin{array}{l}\text { difference mean } \\
{[\mathrm{Cl}]}\end{array}$ \\
\hline Left Static R & $78.04(25.73)$ & \multirow[t]{2}{*}{$p=1.00$} & \multirow{2}{*}{$\begin{array}{l}p=1.12 \times 10- \\
8 \star \star \star\end{array}$} & -11.38 \\
\hline Left Static V & $89.42(31.13)$ & & & {$[-14.88-7.8]$} \\
\hline Right Static R & $76.99(23.24)$ & \multirow[t]{2}{*}{$p=0.91$} & \multirow{2}{*}{$\begin{array}{l}p=5.27 \times 10- \\
5^{\star \star \star}\end{array}$} & -7.12 \\
\hline Right Static V & $84.12(19.24)$ & & & [-10.42 -3.83$]$ \\
\hline Left DynamicR & $\begin{array}{l}115.10 \\
(83.65)\end{array}$ & \multirow[t]{2}{*}{$p=0.0742$} & \multirow[t]{2}{*}{$p=0.153$} & \\
\hline Left DynamicV & $\begin{array}{l}130.76 \\
(54.54)\end{array}$ & & & [-37.29 5.96] \\
\hline $\begin{array}{l}\text { Right Dynamic } \\
\mathrm{R}\end{array}$ & $\begin{array}{l}102.79 \\
(31.46)\end{array}$ & \multirow[t]{2}{*}{$P=1.00$} & \multirow[t]{2}{*}{$p=2.55 \times 10-9$} & -18.97 \\
\hline $\begin{array}{l}\text { Right Dynamic } \\
\mathrm{V}\end{array}$ & $\begin{array}{l}121.76 \\
(30.78)\end{array}$ & & & {$[-24.40-10.40]$} \\
\hline
\end{tabular}

There is no significant difference between the variations in surface and the variations in distance (Left Static, Right Static, Left Dynamic, Right Dynamic, confidence interval for the difference and $p$ value, respectively: $[-1.53 ; 11.53] p=0.13 ;[-11.35 ; 9.75] p=0.88 ;[-3.63 ; 28.64] p=0.12 ;[-2.38 ; 20.85] p=0.11)$. 


\section{Comparison of randomisation arms}

Three out of four results from the dynamic tests showed that the arm did influence performances (distance right dynamic, distance left dynamic, surface left dynamic; t.test Harm Virtual-Real $p$ value, mean arm1, mean arm2, respectively: $[p=0.002$ A1 $=11.15, A 2=27.46] ;[p=0.03, A 1=-5.46, A 2=38.71]$, $[p=0.006, A 1=-1.12, A 2=1.72])$. The participants that started with the real environment saw a less significant deterioration in their performances in the virtual one.

\section{Comparison of the series of 3 tests}

None of the ANOVA of the 3 tests for each measure (2 variables, 4 tests in the real environment, 4 tests in virtual so 16 tests) was statistically significant except for the variable surface on the left dynamic virtual test (ANOVA of the 3 tests; $p=0.0468$ ).

\section{d. Assessment of motion sickness}

The mean of the measure for post-experience motion sickness symptoms (SSQ) was low (mean 2.08, SD 2.63) on a scale of 64 . There was no difference between males and females [mean(SD): $M=1.91$ (3.01); $F=2.26(2.22) ; p$-value $=0.5836]$. This sensitivity correlates to the pre-experience MSSQ score $(r=0.28 p=$ $0.019)$.

\section{Discussion}

\section{a. Interpretation}

We wanted to test the equivalence of postural responses in a real environment and a similar virtual environment. Further to this study we can confirm that static and dynamic postural balance are not equivalent in the same situation in a real and a virtual environment and that most of the time, it is in fact quite different. The surface and distance increased together from the real to the virtual. Undergoing the real situation seemed to improve performances in the virtual situation although it did not lead to equivalence. Repetition of the three tests without a recovery period in between did not result in any learning effect. With an overall alpha risk of $1-(1-0.05)^{\wedge} 16=0.56$, we believe that the significant result on a single test out of 16 is an artefact due to chance. There was no change in performance over the three attempts.

Elsewhere, the very low SSQ score demonstrates good consistency between the real and virtual environment in the 3 dimensions. This means we must exclude the idea of a sensory conflict caused by a delay in perceiving a motion in the virtual environment as causing the deterioration in performance. 
Two questions can be raised, the first being to find out why there is such a difference and the second is whether it is possible to correct the problem. There are a number of possibilities to consider.

\section{- Balance and visual field}

The Oculus Quest 1 has a field of view of $110^{\circ}$ i.e. $55^{\circ}$ per eye ${ }^{34}$. It reaches almost the total range of binocular vision, which is $62^{\circ}$. However the total range of monocular vision (from $62^{\circ}$ to $114^{\circ}$ ) does not return any information in VR. It should be noted that the distribution ratio of photoreceptor cells into rods and cones clearly differs for the central and peripheral visual fields. Neuro-imaging studies have demonstrated that the representation in the far peripheral retina sends inputs to the MT / MST areas (middle temporal/medial superior temporal) ${ }^{35}$. The MST in particular, is connected to the hierarchy of vestibular processing ${ }^{36}$.

The vision provides the essential information about our movements and the environment. It is therefore of prime importance in motor control and balance ${ }^{37}$. Berencsi showed that peripheral vision (monocular) reduced postural sway more than central vision. This probably indicates that the peripheral vision has a greater role in controlling balance than the central vision. Elderly people are more sensitive to any occlusion of the peripheral VF when they are not able to rely as much on reliable proprioceptive inputs (perception of the arch of the foot, the foot, the spine, vestibular information). This means that peripheral vision may influence maintaining balance in a different way from central vision, especially for elderly people 3839 .

When the visual stimulus is presented in the periphery, there are decreased oscillations and this applies more in the anteroposterior $(\mathrm{AP})$ direction than in the medio-lateral $(\mathrm{ML})$ direction, pointing to a characteristic directional specification ${ }^{37}$.

\section{- VR and ocular convergence}

In the real world, accommodation adjusts in synchrony with vergence. In a HMD, this principle is interrupted because objects are presented at variable depths on a screen with a fixed depth $(\sim 5 \mathrm{~cm}$ from the eyes in a HMD) ${ }^{40}$. The dominant characterisation of visual processing identifies a ventral stream (projection from the primary visual cortex, $\mathrm{V} 1$, to the inferior temporal lobe) which is mainly concerned with the perception and identification of visual inputs, and a dorsal stream (projection from V1 to the posterior parietal lobe) which provides visual information that guides action in real time ${ }^{41}$. The earliest results from brain imaging suggest the ventral stream has a greater role in control in VR than it does in the real world ${ }^{42}$. If visually guided skills in VR are indeed based on the ventral stream of control, even in part, then learned skills or those performed with the help of these modified perception inputs may not be representative of their real-world counterparts. The accommodation-vergence conflict in VR also raises questions about the way in which visual performances and/or balance could be affected after using VR. 
The Tychsen study in $2020^{43}$ showed a $9 \%$ deterioration in postural stability in children after 60 minutes of virtual reality gaming. This issue of convergence could explain the poorer balance in VR in the results.

\section{- Balance and avatar}

A related issue that could disrupt normal control of the action is disembodiment in VR. Not only does the addition of a virtual body lead to a greater feeling of presence, but it has an influence on estimation of distance, a fundamental aspect of planning actions ${ }^{44}$. Gonzalez-Franco ${ }^{45}$ noted that in a blind walking task, participants generally underestimated distances by around $10 \%$ in virtual environments, and while the addition of a virtual body reduced error, this was only applicable when users felt incarnated in it. Furthermore, a virtual body has an influence on controlling actions, improves accuracy of steps and lower limb coordination when avoiding obstacles ${ }^{40}$. As such, an inadequate representation of the physical body may be a further obstacle to realistic control of actions in virtual scenarios ${ }^{46}$.

\section{- Subjective verticality}

Visual verticality is the ability of the brain to judge whether something is aligned in the true vertical plane (line of gravity). To maintain adequate standing balance under normal conditions, the brain creates a virtual map of the position of the body in a concrete environment. In this scenario, visual landmarks and information received from muscles other than the eyes ${ }^{47} 48$, from the musculo-skeletal proprioceptors and from the vestibular organs ${ }^{49}$ all generate a feeling of verticality. A number brain conditions, such as cerebrovascular accidents, can damage one or several areas of the central nervous system and vestibular system that are involved in verticality. This damage may lead to errors in calculating verticality of the body and the environment, therefore leading to a loss of balance ${ }^{50}$. It is therefore likely that in our experiment, the loss of peripheral vision associated with the lack of a visible own body disrupted subjective verticality and resulted in more frequent and greater oscillations.

\section{- Effects of the order of environments}

The comparison of the results showed that the order in which the environments were tested influenced the deterioration in balance. If the test was performed in the real environment first, this led to less deterioration in postural responses than when the reverse order was used. It is possible that the person used this time to size up the environment, checking the distances and volumes, helped by seeing their own body. It is unlikely that convergence/divergence was involved because the space was small and there were no objects close enough to require significant ocular convergence.

\section{Generalisability}

We wanted to test the equivalence of postural responses in two comparable real and virtual situations. The Robert et al study ${ }^{18}$ has previously demonstrated with a small sample that VR alters dynamic 
balance but not static balance. Our study shows that both static and dynamic forms of balance are indeed altered by VR.

\section{Limitations}

One of the limitations of this study is the population type, with a relatively young mean age and no balance disorders. It is possible that disruptions in balance may be proportionally greater for populations with an impairment.

\section{Conclusion}

This experiment shows us that when postural responses in a real and virtual environment are compared they are not equivalent, and in fact they are noticeably different. The loss of peripheral vision, the absence of an avatar and the non-convergence/divergence of the eye in VR could explain this outcome of disturbed subjective verticality. For clinicians, therefore, in a situation of remote rehabilitation using immersive VR where balance training is involved, the patient's safety may not be guaranteed. They will also need to take into account this deterioration when choosing the difficulty level for a VR balance rehabilitation programme. For researchers, it is important to find solutions that correct this problem by improving the visual field, adding landmarks to the virtual environment and allowing the participant to see their own movements through an effective avatar.

\section{Declarations}

\section{Author contributions}

PP: Conceptualization, methodology, formal analysis, writing- original draft preparation, editing. ELB.: data curation, preparation, reviewing. MG: preparation, investigation, reviewing. MC: Investigation, reviewing. RC: software. BF: supervision, reviewing. PG: methodology, supervision, reviewing.

\section{Competing Interests Statement}

The authors declare no competing interests.

\section{Ethics approval:}

The South-East France ethics committee approved this study. All participants gave written informed consent before data collection began.

\section{Competing interests :}


The authors have no conflicts of interest to declare

Source(s) of support: : the study is supported by FEDER, (Fonds européen de développement régional), Europeen Union and Brittany France

\section{References}

1. Li, Z., Han, X. G., Sheng, J. \& Ma, S. J. Virtual reality for improving balance in patients after stroke: A systematic review and meta-analysis. Clin. Rehabil, 30, 432-440 (2016).

2. Wang, B. et al. Effect of virtual reality on balance and gait ability in patients with Parkinson's disease: a systematic review and meta-analysis. Clin. Rehabil, 33, 1130-1138 (2019).

3. Phu, S., Vogrin, S., Al Saedi, A. \& Duque, G. Balance training using virtual reality improves balance and physical performance in older adults at high risk of falls. Clin. Interv. Aging, 14, 1567-1577 (2019).

4. Weber, L. M., Nilsen, D. M., Gillen, G., Yoon, J. \& Stein, J. Immersive Virtual Reality Mirror Therapy for Upper Limb Recovery after Stroke: A Pilot Study. Am. J. Phys. Med. Rehabil, 98, 783-788 (2019).

5. Cikajlo, I. \& Peterlin Potisk, K. Advantages of using 3D virtual reality based training in persons with Parkinson's disease: A parallel study. J. Neuroeng. Rehabil, 16, 1-14 (2019).

6. Kalron, A., Fonkatz, I., Frid, L., Baransi, H. \& Achiron, A. The effect of balance training on postural control in people with multiple sclerosis using the CAREN virtual reality system: A pilot randomized controlled trial.J. Neuroeng. Rehabil.13, (2016).

7. Ahmed, N. et al. The Impact of Rehabilitation-oriented Virtual Reality Device in Patients With Ischemic Stroke in the Early Subacute Recovery Phase: Study Protocol for a Phase III, Single-Blinded, Randomized, Controlled Clinical Trial. J. Cent. Nerv. Syst. Dis, 12, 117957351989947 (2020).

8. Ögün, M. N. et al. Effect of Leap Motion-based 3D Immersive Virtual Reality Usage on Upper Extremity Function in Ischemic Stroke Patients. Arq. Neuropsiquiatr, 77, 681-688 (2019).

9. Martinez, A., Paganelli, A. I. \& Raposo, A. Analysing Balance Loss in VR Interaction with HMDs. SBC J. Interact. Syst, 9, 68-81 (2018).

10. Portnoy, S., Reif, S., Mendelboim, T. \& Rand, D. Postural control of individuals with chronic stroke compared to healthy participants: Timed-Up-and-Go, Functional Reach Test and center of pressure movement. Eur. J. Phys. Rehabil. Med, 53, 685-693 (2017).

11. Wajda, D. A., Motl, R. W. \& Sosnoff, J. J. Three-month test-retest reliability of center of pressure motion during standing balance in individuals with multiple sclerosis. Int. J. MS Care, 18, 59-62 (2016).

12. Terra, M. B., Silva, D., Bueno, R. A., Ferraz, M. E. B., Smaili, S. M. \& H. B. \& Center of pressure-based balance evaluation in individuals with Parkinson's disease: a reliability study. Physiother. Theory Pract, 36, 826-833 (2020).

13. Low, D. C., Walsh, G. S. \& Arkesteijn, M. Effectiveness of Exercise Interventions to Improve Postural Control in Older Adults: A Systematic Review and Meta-Analyses of Centre of Pressure 
Measurements. Sport. Med, 47, 101-112 (2017).

14. Woo, B. H. Analysis of Stability on Single-leg Standing by Wearing a Head Mounted Display. Korean J. Sport Biomech, 27, 149-155 (2017).

15. Morel, M., Bideau, B., Lardy, J. \& Kulpa, R. Advantages and limitations of virtual reality for balance assessment and rehabilitation. Neurophysiol. Clin, 45, 315-326 (2015).

16. Luo, H. et al. The effect of visual stimuli on stability and complexity of postural control.Front. Neurol.9, (2018).

17. Kim, A., Darakjian, N. \& Finley, J. M. Walking in fully immersive virtual environments: an evaluation of potential adverse effects in older adults and individuals with Parkinson's disease. J. Neuroeng. Rehabil.14, (2017).

18. Horlings, C. G. C. et al. Influence of virtual reality on postural stability during movements of quiet stance. Neurosci. Lett, 451, 227-231 (2009).

19. Robert, M. T. \& Levin, M. F. Validation of reaching in a virtual environment in typically developing children and children with mild unilateral cerebral palsy. Dev. Med. Child Neurol, 60, 382-390 (2018).

20. Robert, M. T., Ballaz, L. \& Lemay, M. The effect of viewing a virtual environment through a headmounted display on balance. Gait Posture, 48, 261-266 (2016).

21. Parlebas, P. \& Dugas, E. Transfert d'apprentissage et domaines d'action motrice. EPS Educ. Phys. Sport, 48, 41-47 (1998).

22. Migeon, J. P. Le transfert dans les tâches d'ajustement balistique: lancers de basket-ball (FeniXX, 1980).

23. Danion, F. \& Marin, L. Neurosciences comportementales - contrôle du mouvement et apprentissage moteur(2016).

24. Sevinc, V. \& Berkman, M. I. Psychometric evaluation of Simulator Sickness Questionnaire and its variants as a measure of cybersickness in consumer virtual environments.Appl. Ergon.82, (2020).

25. Kim, H. K., Park, J., Choi, Y. \& Choe, M. Virtual reality sickness questionnaire (VRSQ): Motion sickness measurement index in a virtual reality environment. Appl. Ergon, 69, 66-73 (2018).

26. Zhang, L. L. et al. Motion Sickness: Current Knowledge and Recent Advance. CNS Neuroscience and Therapeutics, 22, 15-24 (2016).

27. Munafo, J., Diedrick, M. \& Stoffregen, T. A. The virtual reality head-mounted display Oculus Rift induces motion sickness and is sexist in its effects. Exp. Brain Res, 235, 889-901 (2017).

28. Portney, G. \& Watkins, M. P. Foundations of Clinical Research: Applications to Practice,. 47(2015).

29. Moher, D. et al. CONSORT 2010 Explanation and Elaboration: Updated guidelines for reporting parallel group randomised trials. J. Clin. Epidemiol, 63, e1-37 (2010).

30. Golding, J. F. Predicting individual differences in motion sickness susceptibility by questionnaire. Pers. Individ. Dif, 41, 237-248 (2006).

31. Biernacki, M. P., Kennedy, R. S. \& Dziuda, Å. Zjawisko choroby symulatorowej oraz jej pomiar na przykładzie kwestionariusza do badania choroby symulatorowej - SSQ. Med. Pracy, 67, 545-555 
(2016).

32. Schuirmann, D. J. A comparison of the Two One-Sided Tests Procedure and the Power Approach for assessing the equivalence of average bioavailability. J. Pharmacokinet. Biopharm, 15, 657-680 (1987).

33. Mara, C. A. \& Cribbie, R. A. Paired-samples tests of equivalence. Commun. Stat. Simul. Comput, 41, 1928-1943 (2012).

34. Lynn, M. H., Luo, G., Tomasi, M., Pundlik, S. \& Houston, E. K. Measuring Virtual Reality Headset Resolution and Field of View: Implications for Vision Care Applications. Optom. Vis. Sci, 97, 573-582 (2020).

35. Sharpee, T. O. et al. 25th Annual Computational Neuroscience Meeting: CNS-2016.BMC Neurosci.17, (2016).

36. Chen, A., DeAngelis, G. C. \& Angelaki, D. E. Representation of vestibular and visual cues to self-motion in ventral intraparietal cortex. J. Neurosci, 31, 12036-12052 (2011).

37. Berencsi, A., Ishihara, M. \& Imanaka, K. The functional role of central and peripheral vision in the control of posture. Hum. Mov. Sci, 24, 689-709 (2005).

38. O'Connell, C. et al. Effects of acute peripheral/central visual field loss on standing balance. Exp. Brain Res, 235, 3261-3270 (2017).

39. Piponnier, J. C., Hanssens, J. M. \& Faubert, J. Effect of visual field locus and oscillation frequencies on posture control in an ecological environment. J. Vis, 9, 131-110 (2009).

40. Kim, A., Kretch, K. S., Zhou, Z. \& Finley, J. M. The quality of visual information about the lower extremities influences visuomotor coordination during virtual obstacle negotiation. J. Neurophysiol, 120, 839-847 (2018).

41. Schneider, S. The Blackwell Companion to Consciousness. The Blackwell Companion to Consciousness, https://doi.org/10.1111/b.9781405120197.2007.00056.x (2007).

42. Weiss, P. H., Marshall, J. C., Zilles, K. \& Fink, G. R. Are action and perception in near and far space additive or interactive factors?, 18, 837-846 (2003).

43. Tychsen, L. \& Foeller, P. Effects of Immersive Virtual Reality Headset Viewing on Young Children: Visuomotor Function, Postural Stability, and Motion Sickness. Am. J. Ophthalmol, 209, 151-159 (2020).

44. Mohler, B. J., Creem-Regehr, S. H., Thompson, W. B. \& Bülthoff, H. H. The effect of viewing a selfavatar on distance judgments in an HMD-based virtual environment. Presence Teleoperators Virtual Environ, 19, 230-242 (2010).

45. Gonzalez-Franco, M. \& Berger, C. C. Avatar Embodiment Enhances Haptic Confidence on the Out-ofBody Touch Illusion. IEEE Trans. Haptics, 12, 319-326 (2019).

46. Harris, D. J., Buckingham, G., Wilson, M. R. \& Vine, S. J. Virtually the same? How impaired sensory information in virtual reality may disrupt vision for action. Exp. Brain Res, 237, 2761-2766 (2019). 
47. Guerraz, M. \& Bronstein, A. M. Ocular versus extraocular control of posture and equilibrium. Neurophysiol. Clin, 38, 391-398 (2008).

48. Guerraz, M. \& Bronstein, A. M. Ocular versus extraocular control of posture and equilibrium. Neurophysiol. Clin, 38, 391-398 (2008).

49. Chetana, N. \& Jayesh, R. Subjective visual vertical in various vestibular disorders by using a simple bucket test. Indian J. Otolaryngol. Head Neck Surg, 67, 180-184 (2015).

50. Bonan, I. V. et al. Influence of subjective visual vertical misperception on balance recovery after stroke. J. Neurol. Neurosurg. Psychiatry, 78, 49-55 (2007).

\section{Figures}

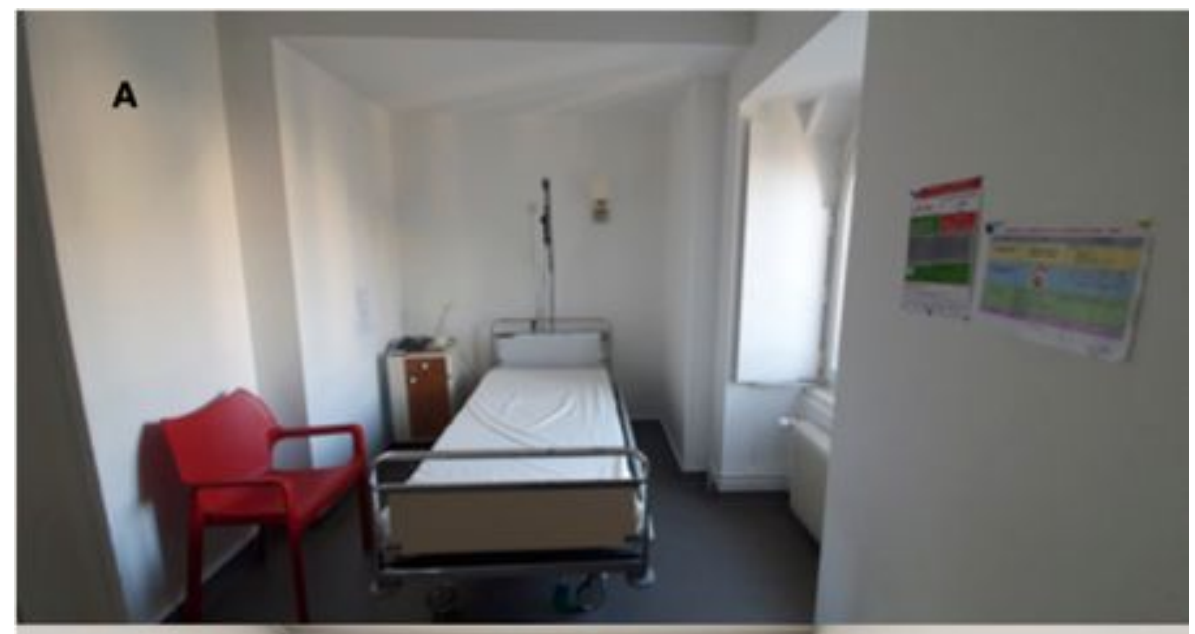

B

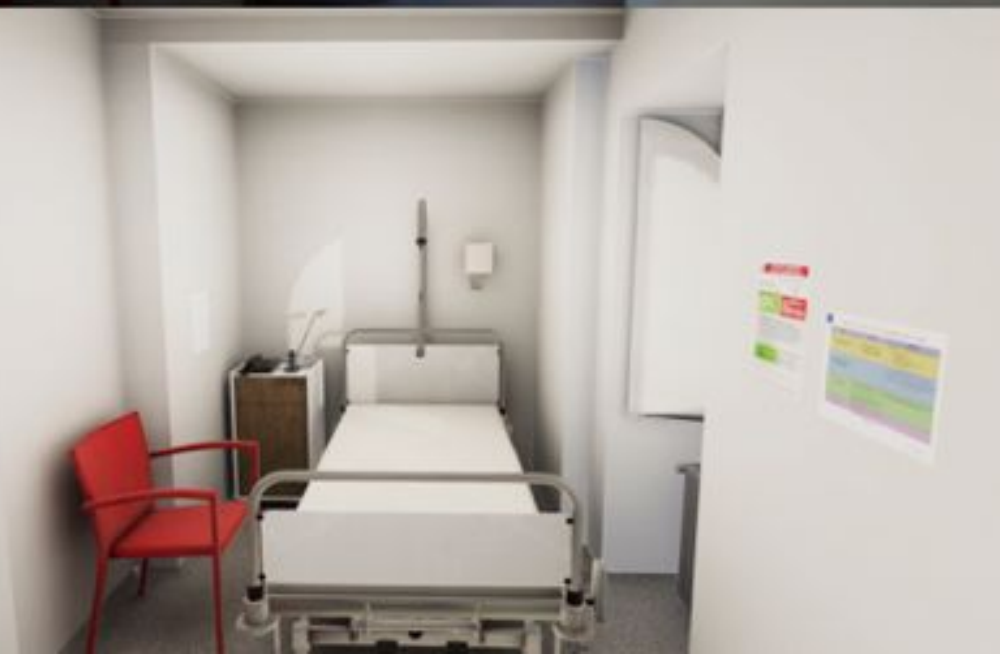

\section{Figure 1}

Real and Virtual environment where the tests are peformed $A=$ real, $B=$ virtual 


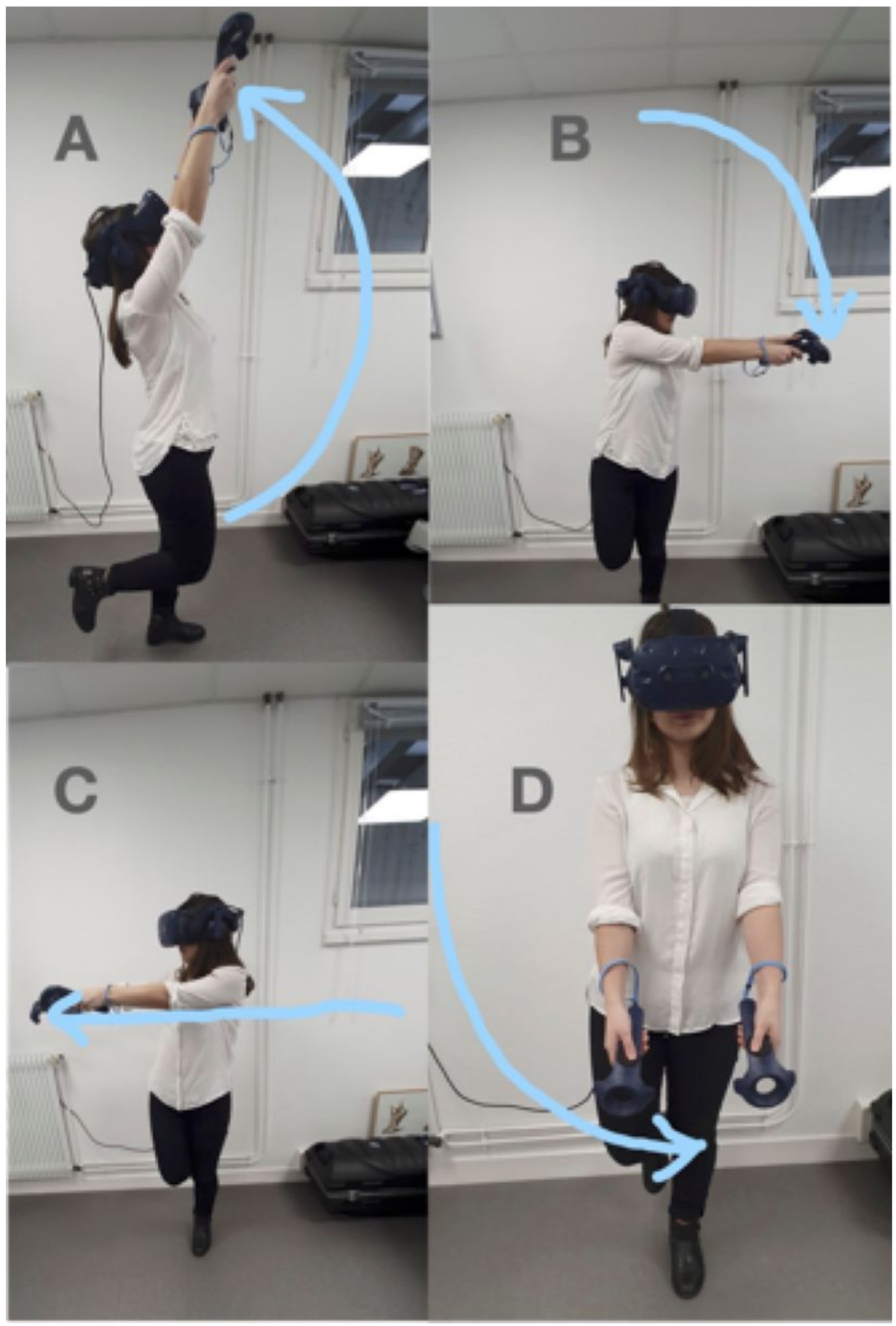

Figure 2

Dynamic balance: A elevation of arms in the sagital plane, B lowering towards the supporting foot in the frontal plane, $\mathrm{C}$ switches to the opposite side in a horizontal plane, $\mathrm{C}$ lowering in the frontal plane to the starting position. 


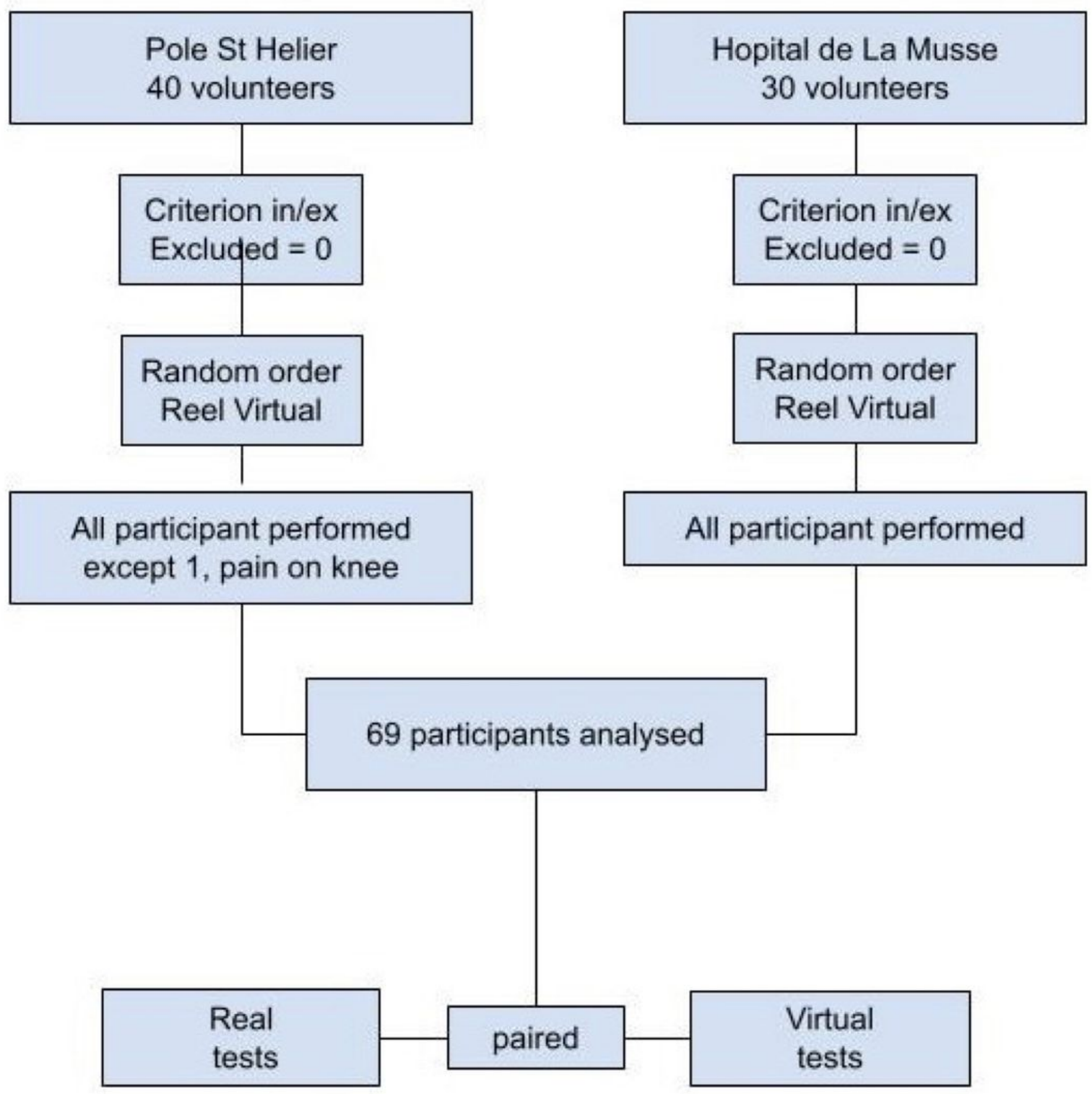

Figure 3

Study design and flow of participants through the trial. 


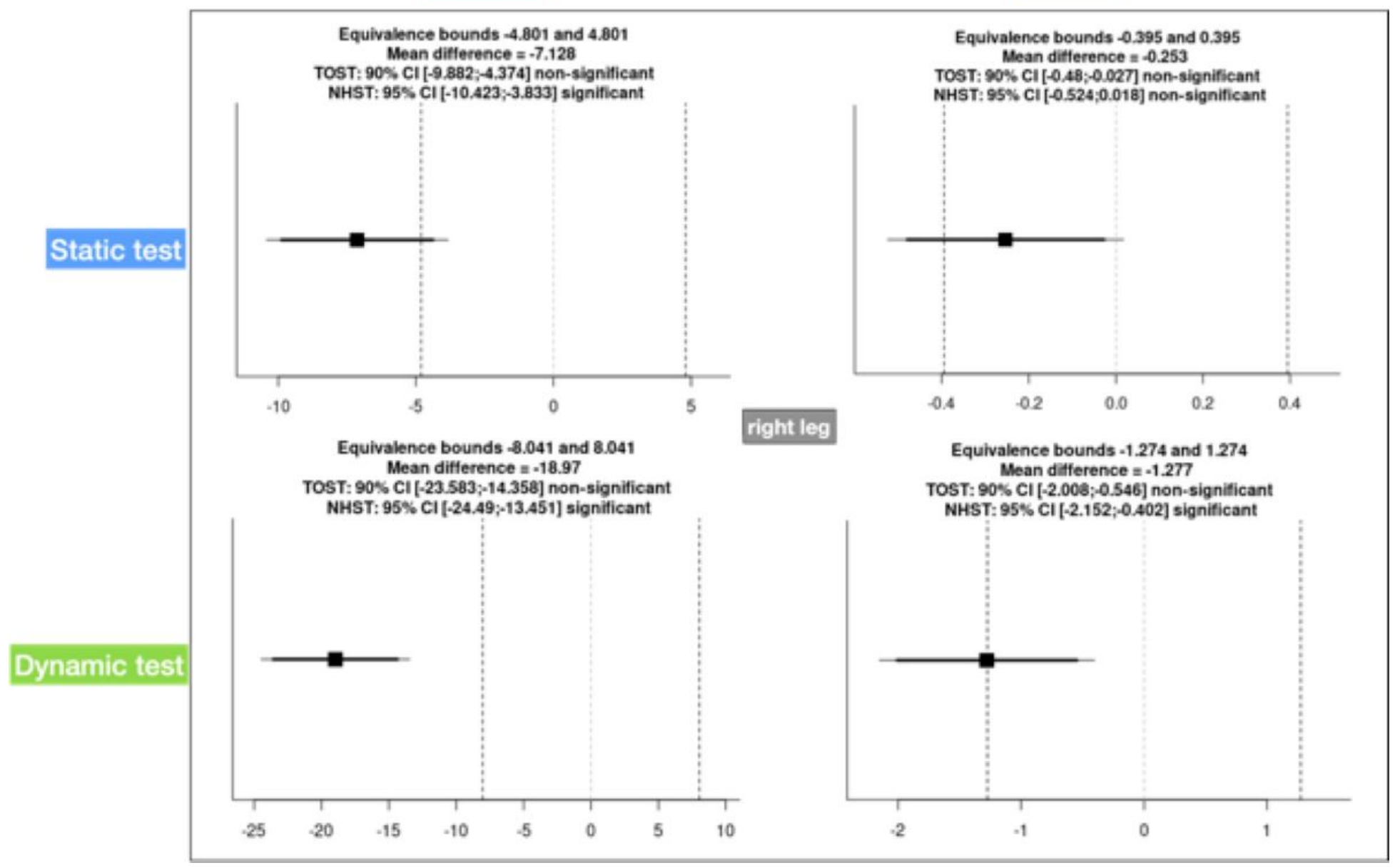

\section{Figure 4}

Right leg equivalence tests (TOST, two on side test) and difference test (NHST, null hypothesis single test) real versus virtual 


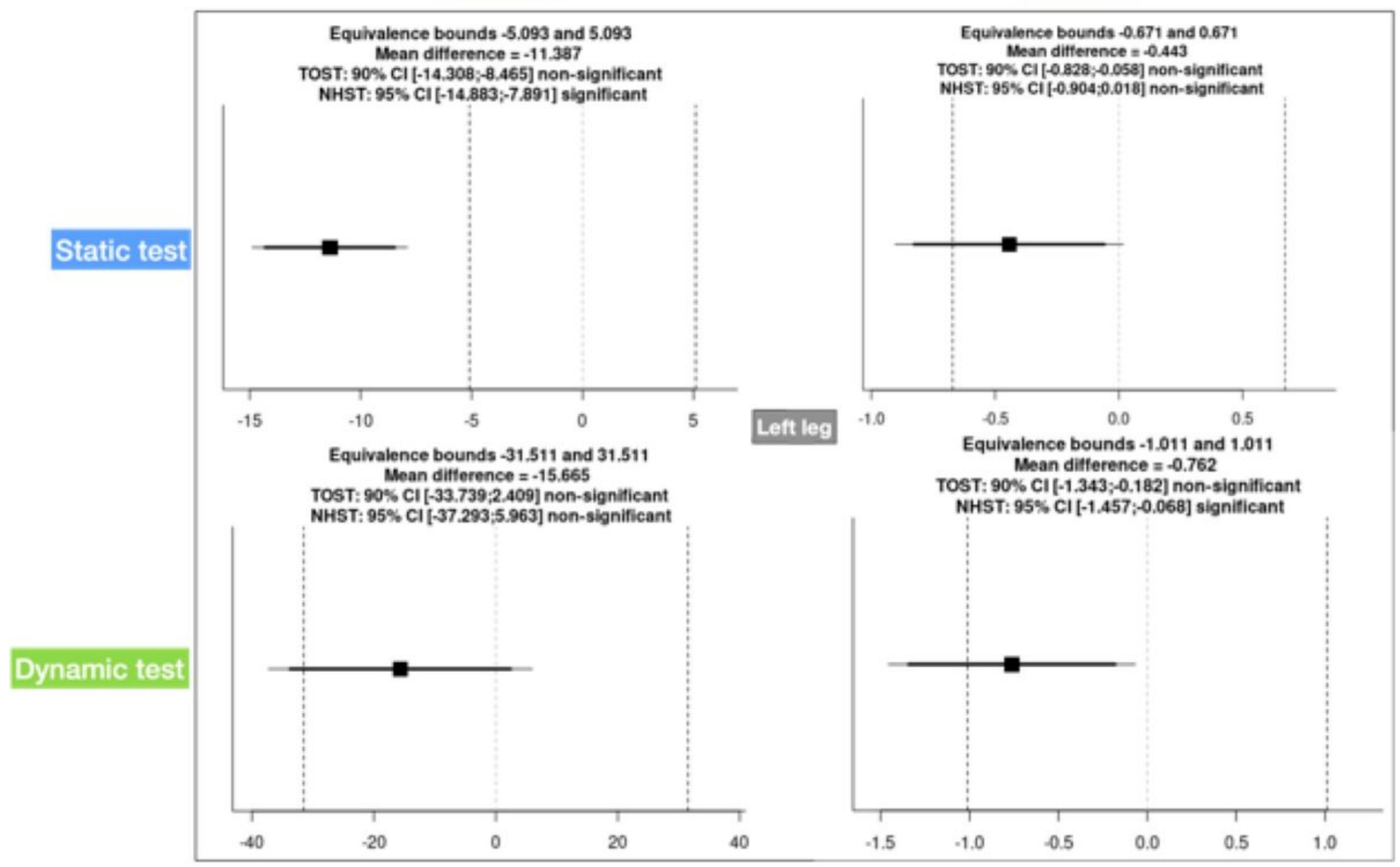

\section{Figure 5}

Left leg equivalence tests (TOST, two on side test) and difference test (NHST, null hypothesis single test) real versus virtual 